\title{
Asthma and Smoking
}

\author{
Arzu Didem Yalçın ${ }^{1 *}$, Gülşen Göney ${ }^{2}$ \\ ${ }^{1}$ Internal Medicine, Allergy and Clinical Immunology, Academia Sinica, Genomics Research Center, Taipei, Taiwan, University of Medical Science, Antalya Hospital, \\ Antalya, Turkey
}

${ }^{2}$ Gazi University, Faculty of Pharmacy, Department of Toxicology, Hipodrom, Ankara, Turkey

*Corresponding author: Arzu Didem Yalçın, Internal Medicine, Allergy and Clinical Immunology, Academia Sinica, Genomics Research Center, Taipei, Taiwan, University of Medical Science, Antalya Hospital, Antalya, Turkey, E-mail: adidyal@yahoo.com

Received date: May 24, 2017; Accepted date: May 25, 2017; Published date: June 03, 2017

Copyright: (c) 2017 Yalçın AD, et al. This is an open-access article distributed under the terms of the Creative Commons Attribution License, which permits unrestricted use, distribution, and reproduction in any medium, provided the original author and source are credited.

Citation: Yalçin AD, Göney G (2017) Asthma and Smoking. J Allergy Ther 8: e120. doi:10.4172/2155-6121.1000e120

\section{Editorial}

Allergic diseases, such as asthma are a world public health concern. Asthma, a common and chronic disease of the airways, and smoking are so common within the world's population and also their prevalence has increased markedly over. Indeed smoking and asthma pandemic have huge implications for public health. Tobacco smoke is probably the most significant source of toxic chemical exposure. And we know that toxic chemical substance exposure increased formation of health problems related with smoking as asthma.

Asthma has a multifactorial cause involving both genetic and environmental factors. Results show that asthma can depend on exposure to an environmental factor, as environmental tobacco smoke (ETS). ETS is a potential risk factor for asthma, would improve the ability to map genes for asthma. Especially, ETS increases morbidity for children with asthma [1,2]. Studies indicate that more than 200,000 episodes of childhood asthma per year have been attributed to parental smoking in the United States [3]. Infants and children are more prone to the risks related to ETS exposure than adults. Children of smoking mothers have an increased risk of respiratory diseases during infancy [4]. Analyses results that maternal smoking of 0.5 packs per day was identified as an independent risk for children's use of asthma medications and for asthma developing especially in the first year of life. As a result of maternal smoking is associated with higher rates of asthma, an increased likelihood of using asthma medications, and an earlier onset of the disease [5].

Children are effected by nicotine that is coming from indirect exposure to tobacco smoke. Residual nicotine that persists in high concentrations on the interior surfaces, including clothing that is a third-hand smoke. Ozone and related atmospheric oxidants react with nicotine smoke or smoke coming from the second-hand smoke, giving the smallest particles with high risk of asthma. Also ozone reacts with nicotine or second-hand smoke to form ultrafine particles with a high asthma hazard index $[4,6]$. In addition, tobacco smoking may be associated with an increased incidence rate of adult-onset asthma, especially among women [7].

The importance of tobacco smoking for adult onset asthma is controversial. Some studies have failed to show an increased risk among smokers $[1,8,9]$ while others have not found an increased risk [10] some of them found an increased risk mainly among females
[5,7], some of them found an increased risk mainly among infants and children [2,5]. In addition some of them indicate if environmental tobacco smoke is considered a co-factor provoking wheezing attacks, rather than a cause of the underlying asthmatic tendency [8].

Researchers indicate that adults with asthma do not appear to selectively avoid cigarette smoking. Specific smoking prevention and cessation efforts should be targeted to adults with asthma.

Last, but not least, continued vigorous efforts are required to discourage all women and girls from taking up smoking and to encourage those who smoke to quit. This is particularly pertinent for asthmatic women who are pregnant or planning a pregnancy.

\section{References}

1. Colilla S, Nicolae D, Pluzhnikov A, Blumenthal MN, Beaty TH, et al. (2003) Evidence for gene-environment interactions in a linkage study of asthma and smoking exposure. J Allergy Clin Immunol 111: 840-846.

2. Halterman JS, Fagnano M, Conn KM, Szilagyi PG (2006) Do parents of urban children with persistent asthma ban smoking in their homes and cars?. Ambul Pediatr 6: 115-119.

3. Office of Environmental Health Hazard Assessment (2005) Health effects of exposure to environmental tobacco smoke: final report. Sacramento: California Environmental Protection Agency.

4. Merritt TA, Mazela J, Adamczak A, Merritt T (2012) The impact of secondhand tobacco smoke exposure on pregnancy outcomes, infant health, and the threat of third-hand smoke exposure to our environment and to our children. Przegl Lek 69: 717-720.

5. Weitzman M, Gortmaker S, Walker DK, Sobol A (1990) Maternal smoking and childhood asthma. Pediatrics 85: 505-511.

6. Ferrante G, Simoni M, Cibella F, Ferrara F, Liotta G, et al. (2015) Thirdhand smoke exposure and health hazards in children. Monaldi Arch Chest Dis 79: $38-43$.

7. Toren K, Hermansson BA (1999) Incidence rate of adult-onset asthma in relation to age, sex, atopy and smoking: a Swedish population-based study of 15813 adults. Int J Tuberc Lung Dis 3: 192-197.

8. Strachan DP, Cook DG (1998) Parental smoking and childhood asthma: longitudinal and case-control studies. Thorax 53: 204-212.

9. Flodin U, Ponsson P, Ziegler J, Axelson O (1995) An epidemiologic study of bronchial asthma and smoking. Epidemiology 6: 503-505.

10. Vesterinen E, Kaprio J, Koskenvuo M (1988) Prospective study of asthma in relation to smoking habits among 14,729 adults. Thorax 43: 534-539. 